\title{
ADEQUACY OF VILLALOBOS METHOD TO ADJUST EDDY COVARIANCE LATENT HEAT FLUX
}

\author{
Antonio Martínez-Cob
}

Tenured Scientist

Address: Departamento de Genética y Producción Vegetal (EEAD) Laboratorio Asociado de Agronomía y Medio Ambiente (DGA-CSIC) Apartado 202, 50080 Zaragoza (SPAIN)

Phone: (34) 976716086

Fax: (34) 976716145

E-mail: macoan@eead.csic.es

\section{Short running title}

Adjusting eddy covariance latent heat 


\section{SUMMARY}

Latent $(L E)$ and two sets of sensible $(H)$ heat fluxes $\left(H_{e c}\right.$ and $\left.H_{t 2}\right)$ were measured with an eddy covariance system (sonic anemometer, krypton hygrometer, two fine-wire thermocouples) over grass (six days, summer 1997) and wheat (seven days, late spring 1999) in NE Spain. The objective was to evaluate a method to correct eddy covariance underestimation due to horizontal sensor displacement (Villalobos, 1997), based upon the similarity of covariance loss for both $L E$ and $H$. First, this assumption was examined by regression analyses of measured lysimeter $L E\left(L E_{l y s}\right)$ versus eddy covariance $L E\left(L E_{e c}\right)$ and $H_{e c}$ versus $H_{t 2}$. In general, regression slopes of $L E$ and $H$ were relatively similar, although this similarity depended upon the atmospheric stability conditions. For grass, $L E_{e c}$ was significantly lower than $L E_{l y s}$, while for wheat there was a close agreement among $L E_{\text {lys }}$ and $L E_{e c}$. Ratios of horizontal sensor displacement to measurement sensor height above zero plane displacement $\left(s / z_{d}\right)$ were about 0.36 0.40 for grass and 0.11 for wheat. A further regression analysis was performed to compare $L E_{l y s}$ to corrected eddy covariance $L E$ ( $\left.L E_{e c v}\right)$ values following Villalobos (1997). That correction significantly improved eddy covariance $L E$ values measured over grass but only in some cases, mostly under unstable (near to neutral) atmospheric conditions. It can be concluded that low $s / z_{d}$ ratios (Iess than 0.1 ) are preferable to reduce loss in covariance of $L E$. If the use of higher $s / z_{d}$ ratios can not be avoided, the Villalobos method may reduce the expected loss in covariance but only under limited conditions. In these situations other solutions to reduce loss in covariance should be further investigated.

\section{INTRODUCTION}

Quantification of crop evapotranspiration is important for understanding hydrological processes in agriculture, in particular as related to management practices involving irrigation design, efficiencies and scheduling. Additional areas include calibration and validation of crop models. There are several methods to measure crop evapotranspiration, such as lysimeters, micrometeorological systems, water balance, and remote sensing, among others. Each of these methods has their own assumptions, spatial and temporal measurement scales, complexity, and expense.

Weighing lysimeters have been frequently used to measure crop evapotranspiration during a crop growing season (Allen et al., 1991; Jensen et al., 1990). According to the American Society of Civil Engineers (ASCE) (1996), these instruments can precisely measure water losses from soil and vegetated surfaces. However, lysimeters are expensive and non portable, and their use is limited to research stations. Consequently, there is a need for alternative methods that are 
less expensive and portable. In general, these methods are based on the measurement of the energy balance components: latent, sensible and soil heat fluxes, and net radiation. Eddy covariance theory can provide accurate and direct measurements of the evaporative (latent heat) flux with a sound theoretical basis (ASCE, 1996; Foken and Wichura, 1996; Kizer et al., 1990; Monteith and Unsworth, 1990).

Eddy covariance systems have been increasingly used in recent years for a number of studies, where fluxes of latent and sensible heat, momentum and other gases have been measured. This type of research has been carried out over different land surfaces (herbaceous crops, natural grasses, forests and others), and with different research objectives. The following studies are mentioned among others: Aubinet (1997), Baldocchi and Meyers (1998), Brunet et al. (1994), Dugas et al. (1991), Harazono et al. (1998), Kizer et al. (1990) and Valentini et al. (1995).

However, several aspects of eddy covariance measurements should be addressed before these systems may be used for precise, continuous and routine measurement of crop evapotranspiration. Foken et al. (1995) and Foken and Wichura (1996) have presented a thorough review of the constraints and requirements of this technique. These authors have pointed out that there may be a loss in covariance caused by the physical separation of the sensors involved, which could lead to an underestimation of the fluxes being measured. This event has been reported previously for latent heat flux (Dugas et al., 1991; Dyer et al., 1982). There have been previous attempts to address this problem (Koprov and Solokov, 1973; Moore, 1986). Moore's corrections only indicate the magnitude of the effect as they are based on model spectra that can not be considered as universally applicable (Foken et al., 1995; Foken and Wichura, 1996).

Recently, Villalobos (1997) has proposed a correction based on the assumption that loss in covariance due to horizontal sensor displacement for sensible heat $(H)$ is equal to that for latent heat flux $(L E)$ due to similar co-spectra for both variables. If so, additional measurements of the temperature at the same point as the hygrometer would provide for correcting the latent heat flux measured using eddy covariance. To demonstrate his hypothesis, Villalobos (1997) used an eddy covariance system, with an additional thermocouple attached to the hygrometer, to record $L E$ and two sets of $H$ measurements. Eddy covariance $L E$ values were multiplied by the ratio of the two covariances between vertical wind and temperature $\left(\overline{w^{\prime}} T^{\prime}\right)$ recorded at the same time period. Villalobos (1997) compared the slopes of the regressions of both sets of $H$ values against the slopes of the regressions of corrected $L E$ on measured $L E$ for different days and atmospheric stability conditions, and found the slopes to be similar. However, this demonstration of the Villalobos hypothesis is thin as the ratio of the two covariances $\overline{w^{\prime}} T^{\prime}$ is in fact the slope of the regression of 
both $H$ sets of values, if the intercept is not significantly different than 0 . And therefore, no other result but similarity of slopes for $L E$ and $H$ should have been expected.

Nevertheless, the assumption of similarity of co-spectra for both variables is valid. An independent evaluation of Villalobos (1997) hypothesis seems worthwhile. The objectives of this paper, within the frame of studying the loss in covariance of $L E$ due to horizontal sensor displacement, are the following: 1) to compare independently measured weighing lysimeter and eddy covariance $L E$ values; 2 ) to compare the slopes of regressions of $L E$ against those of two sets of $H$ values measured following Villalobos $(1997) ; 3)$ to evaluate the feasibility of the correction proposed by Villalobos (1997) by comparing noncorrected and corrected eddy covariance $L E$ values against lysimeter $L E$. Measurements were taken over two crops (grass and wheat) under the semiarid environment of the middle Ebro River Valley (NE Spain).

\section{MATERIAL AND METHODS}

The research was conducted on an experimental farm located in the middle Ebro River Valley (NE Spain), along the terraces of Gállego

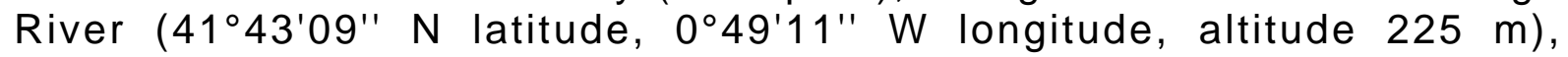
about $8 \mathrm{~km}$ from where both rivers meet. This is an irrigated area of about 5-7 km width stretching along the Gállego River for about 20-25 $\mathrm{km}$. Soils in the experimental site are Typic Xerofluvent. Most crops in the area are corn, alfalfa, other pastures, fruit tree orchards, vegetables, and natural riparian vegetation. The climate is semiarid mediterranean continental with an average annual precipitation of about $330 \mathrm{~mm}$. The wettest periods are spring (April and May) and fall (October and November) (Faci et al., 1994).

Measurements were taken over two adjacent 1 ha $(100 \mathrm{~m} \times 100$ $\mathrm{m})$ plots. The first plot was uniformly covered with grass (Festuca arundinacea Moench. cv. Demeter). Measurements over grass were taken during six days in the summer of 1997 (7, 15, 17 and 31 July, and 4 and 5 September). Crop heights $(h)$ during the measurement periods for grass varied between $0.14 \mathrm{~m}$ ( 7 July) and $0.18 \mathrm{~m}$ ( 17 and 31 July), being $0.16 \mathrm{~m}$ on 4 September and $0.17 \mathrm{~m}$ on 15 July and 5 September. In the second plot, wheat (Triticum aestivum cv. Anza) was grown. Wheat was sown on December 18, 1998 and harvested on July 1, 1999. Measurements over wheat were taken during seven days of late spring in 1999 (24, 25 and 26 May, and 3, 5, 7 and 8 June) when the wheat crop was at the end of the full growth stage and the beginning of senescence. Crop height during the measurement period over wheat was $0.90 \mathrm{~m}$.

A weighing lysimeter, $1.7 \mathrm{~m}$ depth and $6.3 \mathrm{~m}^{2}$ effective surface area, was located in the center of each plot. Each lysimeter was equipped with two drainage tanks operating at atmospheric pressure and at an user-defined suction pressure. Both tanks were suspended 
from the lysimeter bottom, and thus jointly weighed. Drainage tanks were emptied periodically. A load cell connected to a Campbell Scientific datalogger (CR500) recorded lysimeter mass losses (every $0.5 \mathrm{~s}$ ) from which 30-min evapotranspiration rates were obtained. The combined resolution of both load cell and datalogger allowed to detect mass losses of about $0.3 \mathrm{~kg}\left(0.05 \mathrm{~mm}\right.$ water depth or about $\left.30 \mathrm{~W} \mathrm{~m}^{-2}\right)$. Identical management practices (sprinkler irrigation, fertilization, grass clippings) were performed simultaneously in both the lysimeter and surrounding plot. Table 1 lists the precipitation and irrigation events during the measurement time periods, and crops surrounding experimental field plots.

An automatic weather station (CR10 Campbell Scientific) was located next to each lysimeter. Table 2 lists variables recorded (30-min intervals), measurement sensor height, sensor model and manufacturer. A Campbell Scientific eddy covariance station was installed next to each lysimeter and oriented to the north west as this is in general the most frequent wind direction for that area. Sensors included a 1-D sonic anemometer, a fine wire thermocouple attached to the anemometer (model 127, copper-constantan, $0.013 \mathrm{~mm}$ diameter) and a krypton hygrometer. A second fine wire thermocouple (model TCBR-3, copperconstantan, $0.008 \mathrm{~mm}$ diameter) was attached to the hygrometer. Horizontal displacement between the sonic anemometer and the hygrometer was $0.13 \mathrm{~m}$. Measurement sensor heights $(z)$ were $0.45 \mathrm{~m}$ (grass) and $1.75 \mathrm{~m}$ (wheat) above the ground.

Eddy covariance measurements were made at a frequency of 10.7 $\mathrm{Hz}$. Eddy covariance latent heat flux $\left(L E_{e c}\right)$ values were obtained from covariances between vertical wind and water vapor fluctuations ( $\overline{w^{\prime} q^{\prime}}$ ) (Monteith and Unsworth, 1990; Foken and Wichura, 1996) and corrected as indicated by Tanner et al. (1993) to take into account the effect of heat flux and oxygen density fluctuations on krypton hygrometer water vapor flux measurements. Eddy covariance sensible heat flux values, $H_{e c}$ and $H_{t 2}$, were obtained from covariances between vertical wind and temperature fluctuations measured with the 127 thermocouple $\left(\overline{w^{\prime} T_{1}^{\prime}}\right)$ and the additional TCBR-3 thermocouple $\left(\overline{w^{\prime} T_{2}^{\prime}}\right)$, respectively (Monteith and Unsworth, 1990; Foken and Wichura, 1996). Eddy covariance data was recorded every 10 minutes and averaged for 30 -min values. Data were removed from analysis during periods when wind flowed from the back of the sensors to avoid distortion of fluxes measured (Foken and Wichura, 1996). This occurred for south east (SE) wind directions (124 to $\left.146^{\circ}\right)$.

Several papers have shown the similarity of co-spectra for sensible and latent heat (Anderson et al., 1986; Ohtaki, 1985; Redford et al., 1980). This similarity led to Villalobos (1997) to hypothesize that the fractional loss in covariance due to horizontal sensor displacement for $H$ is equal to that for $L E$. Villalobos (1997) proposed to use an additional thermocouple attached to the hygrometer near the vapor 
measurement path. Thus, two sets of $H$ values would be obtained such that the ratio of one to the other would represent the loss in covariance for $H$, and, following Villalobos hypothesis, the loss in covariance for $L E$ due to horizontal sensor displacement.

Therefore, eddy covariance $L E$ values, corrected following Villalobos (1997) $\left(L E_{e c v}\right)$, were computed from the expression:

$$
L E_{e c v}=L E_{e c} \frac{\overline{w^{\prime} T_{1}^{\prime}}}{w^{\prime} T_{2}^{\prime}}
$$

The two sets of eddy covariance $L E$ values ( $L E_{e c}$ and $L E_{e c v}$ ) were compared to lysimeter $L E$ values $\left(L E_{l y s}\right)$ by simple linear regression. The same procedure was used to compare both sets of $H$ values $\left(H_{e c}\right.$ and $\mathrm{H}_{t 2}$ ). Before these comparisons were performed, quality of eddy covariance data was evaluated using the instationarity test proposed by Foken and Wichura (1996) and described in Appendix 1. Stationarity means that statistics do not vary in time. The lack of stationarity is one of the most serious problems in turbulence measurements (Foken and Wichura, 1996).

Closure of the eddy covariance measurements was evaluated by computing the closure number $(C)$ for each analyzed day as follows:

$$
C=\frac{1}{n} \sum_{i=1}^{n}\left(R_{n}-G-H_{e c}-L E_{e c}\right)_{i}
$$

where $n$ is the number of 30-min periods available for a given day, $R_{n}$ is net radiation and $G$ is soil heat flux. All terms in equation (2) are expressed in $\mathrm{W} \mathrm{m}^{-2}$.

To quantify atmospheric stability during the measurement periods, approximate $z / L$ values were estimated following Villalobos (1997), with friction velocity calculated from wind speed recorded at the weather stations assuming neutral conditions (ASCE, 1996).

\section{RESULTS AND DISCUSSION}

The general meteorological conditions during the measurement periods over grass and wheat are summarized in Figures 1 and 2, and Table 3. Figure 1 shows the daily evolution of net radiation values during the measurement periods for grass (1997). Typical values of net radiation for clear skies were predominant during four of the studied days while overcast conditions occurred during the $15^{\text {th }}$ and, particularly, the $17^{\text {th }}$ of July. Figure 2 shows the daily evolution of net radiation during the measurement periods for wheat (1999). A variable degree of cloudiness occurred during these periods, with the 3 June the sunniest and the 7 June the cloudiest days. In general, these values can be considered as typical during late spring. 
During the measurement periods for grass, moderate wind speeds were recorded in July. However, strong average 30-min wind speeds above $6.0 \mathrm{~m} \mathrm{~s}^{-1}$ were recorded during the daytime periods on 17 July. Wind speeds near $5.0 \mathrm{~m} \mathrm{~s}^{-1}$ were recorded on 15 July for early evening. Low wind speeds (below $2.0 \mathrm{~m} \mathrm{~s}^{-1}$ ) occurred on 4 September, while wind speeds were slightly higher on 5 September. During the measurement periods for wheat, low wind speeds (below $2.0 \mathrm{~m} \mathrm{~s}^{-1}$ ) occurred during 24 May and 25 May, while moderate wind speeds were recorded the other five days. Average wind speeds above $5.0 \mathrm{~m} \mathrm{~s}^{-1}$ were not recorded during these periods.

Table 3 lists additional meteorological data recorded during the measurement periods over both grass and wheat: mean temperature, ratio of measured $L E_{\text {lys }}$ to net radiation ( $\left.L E R\right)$ and predominant wind direction. $L E R$ values above 1.0 suggest that advective conditions occurred during 15 and 17 July 1997. Wind direction was variable during all analyzed days.

Figure 3 shows the instationarity test for the covariance $\overline{w^{\prime} q}$ for both grass and wheat. Foken and Wichura (1996) indicate that stationarity can be assumed if differences between covariances, computed from equations 3 and 4 (Appendix 1) are less than $30 \%$. Instationarity tests for the other two covariances $\left(\overline{w^{\prime} T_{1}^{\prime}}\right.$ and $\overline{w^{\prime} T_{2}^{\prime}}$ ) were also similar. Results from Figure 3 suggest that the stationarity criteria was met and that data quality was good. Foken and Wichura (1996) also suggested that the lack of stationarity reflects the lack of homogeneity of crop surface surrounding measurement spot. Then, it can be stated that field plots were homogeneous and that fetch requirements were achieved. For the sensor and crop heights seen during those periods, fetch requirements for neutral conditions, computed following ASCE (1996), were about 24 to $27 \mathrm{~m}$ for grass and about $75 \mathrm{~m}$ for wheat. The dimensions of the field plots warranted these fetch requirements during measurements over grass for all periods regardless of wind direction, but not strictly for the wheat case. The crops surrounding the wheat plot during the measurement periods were pastures, wheat and corn sown at the beginning of May 1999. Thus steep changes from one vegetated surface to the other near the wheat plot were minimal and it could be expected that fetch requirements were achieved as the instationarity tests suggest.

Figures 4 and 5 show measured lysimeter and eddy covariance evapotranspiration rates $(E T)$ for grass and wheat, respectively. For grass (Figure 4), lysimeter $E T$ ( $E T_{\text {lys }}$ ) was significantly greater than eddy covariance $E T\left(E T_{e c}\right)$ for all days, particularly during daylight hours. These differences were relatively small on 4 September and the largest differences were observed on 15 July. For wheat, differences between $E T_{\text {lys }}$ and $E T_{\text {ec }}$ were comparatively small for all days (Figure 5 ), except on 8 June. In general terms, lysimeter values showed a higher variability than eddy covariance ones, particularly for grass on 
15 and 17 July. Lysimeters, as any other measurement device, are subject to errors as those due to the pressure force exerted by wind over the lysimeter surface (Howell et al., 1995). It should also be reminded that lysimeter resolution (about $30 \mathrm{~W} \mathrm{~m}^{-2}$ ) was lower than eddy covariance resolution. Then, higher lysimeter uncertainty (and thus higher variability) should be expected under high wind conditions, particularly if net radiation is also low as it occurred for grass on 15 and 17 July.

Table 4 presents the results of simple linear regressions $(y=c x)$ between $L E_{e c}$ (independent variable, $x$ ) and $L E_{\text {lys }}$ (dependent variable, $y)$ for both grass and wheat. Regressions were forced through the origin as nearly all intercepts were not significantly different than $0(\alpha=0.95)$. Results are presented for: 1 ) all 30 -min periods with available data; 2 ) 30 -min periods with unstable conditions $(z / L<0)$; and 3 ) 30-min periods with stable conditions $(z / L>0)$. Coefficients of determination were generally high, except for some stable 30-min period cases.

The regression slopes indicate that there was better agreement between lysimeter and eddy covariance $L E$ values for wheat than for grass as Figures 4 and 5 show. According to regression slopes ("all 30 min periods" cases), grass $L E_{\text {lys }}$ was 42 to $52 \%$ higher than grass $L E_{e c}$ for 7, 17 and 31 July and 5 September, while it was only about $14 \%$ higher on 4 September. The high regression slope (2.5) obtained for 15 July ("all 30-min periods" case) was striking. For this day, six 30-min periods with SE wind direction were removed from analysis due to the potential flow distortion induced by the supporting sensor masts (Foken and Wichura, 1996). Nevertheless, the results suggest that this flow distortion may have significantly occurred also during other periods for which predominant wind directions were south south east (SSE) and east south east (ESE). However, these periods were not removed in order to compare this result with the one observed for wheat during 26 May, 1999.

Differences in regression slopes between the other five different days were likely due to different meteorological conditions. Note that the regression slope for $L E$ on 4 September was not significantly different than $1.0(\alpha=0.95)$ (Table 4). This was a low wind speed day for which mechanical turbulence can be assumed to be significantly lower than on the other days. Regression slope for LE on 5 September, as well as wind speed, was intermediate between that for 4 September and that for 7, 17 and 31 July. Likewise, net radiation values on September were lower than those observed on July (Figure 1) leading to a likely lower convective turbulence as less energy was available. These circumstances, lower mechanical and convective turbulence, could explain the better agreement between $L E_{l y s}$ and $L E_{e c}$ observed for the two September days analyzed.

$L E_{l y s}$ and $L E_{e c}$ showed a close agreement for wheat. Thus, regression slopes ("all 30-min periods" cases) were not significantly 
different that $1.0(\alpha=0.95)$, except on 8 June. It can be noted that eddy covariance $L E$ during 24,25 and 26 May was slightly lower than lysimeter $L E$, while for the other four days the opposite was observed. During these measurement periods, the wheat crop was at the end of the full growth stage and beginning of senescence. Evapotranspiration was reduced by senescence by 8 June and sensible heat flux exceeded latent heat flux. Perhaps, lysimeter wheat was slightly closer to physiological maturity than wheat in surrounding area, although there was not visual evidence of differences in development stages and yields were similar.

Figures 6 and 7 show the daily evolution of $H_{e c}$ and $H_{t 2}$ over grass and wheat, respectively. For grass, $H_{e c}$ was higher than $H_{t 2}$ during daytime periods, while it was lower than $H_{t 2}$ during late afternoon periods for some days. Both variables appeared to be closer during the night time hours. For wheat, agreement between $H_{e c}$ and $H_{t 2}$ was higher and significant differences were not evident from Figure 7.

Table 5 presents the results of the simple linear regressions $(y=$ $c x$ ) between $H_{e c}$ (dependent variable, $y$ ) and $H_{t 2}$ (independent variable, $x$ ) for both grass and wheat. Regressions were forced through the origin as for the $L E$ case. Similarly, results are presented for: 1) all 30-min periods with available data; 2$) 30$-min periods with unstable conditions $(z / L<0)$; and 3$) 30$-min periods with stable conditions $(z / L>0)$. All coefficients of determination were generally high, particularly for the wheat case.

For grass ("all 30-min periods" cases), regression slopes for $H$ were relatively similar to those for $L E$ on four of the analyzed days. Nevertheless, note that regression slopes for $H$ were smaller than those for LE. Regression slope for $H$ on 15 July was of the same magnitude than that obtained on the other days, but $17 \mathrm{July}$, and thus quite different than that for $L E$. Results observed on 15 July will be further discussed later. Regression slope for $H$ on 17 July was also quite different than that observed for $L E$. Surprisingly, this regression slope was below 1.0 although not significantly $(\alpha=0.95)$. 17 July was strongly windy (Figure 3 ) and advective (Table 3 ). $H_{\text {ec }}$ was already lower than $H_{t 2}$ for the early afternoon on 17 July while this circumstance only happened in late afternoon for the other days (Figure 8). No explanation was evident for this behavior.

For wheat ("all 30-min periods" cases), regression slopes for $H$ were significantly above $1.0(\alpha=0.95)$ on most days (Table 5). These results suggest a small loss in covariance for $H$, ranging from 3 to 12 $\%$, except on 26 May for which regression slope was less than 1.0 although not significantly $(\alpha=0.95)$. Results for $H$ for wheat were opposed to those seen for grass. Thus, loss in covariance for $H$ was lower than that for $L E$ for grass, while it was higher for wheat. As discussed previously, lysimeter wheat was closer to physiological maturity than the surrounding wheat. 
Table 6 lists the closure numbers computed for each measurement day for both grass and wheat. These closure numbers are given in absolute values as well as in relative terms, as the percentage of the whole range of $L E_{e c}$ values recorded for each single day. Assuming as adequate a closure number within $10 \%$ (Harazono et al., 1998), these numbers indicate that energy balance closure was only achieved for wheat for most of the analyzed days. The lack of energy balance closure suggest that measurements were not adequate likely because of the loss of covariance due to horizontal displacement. As this loss of covariance was greatly reduced for wheat, better closure numbers were obtained in this case.

Regression slopes for $L E$ and $H$ for the "unstable 30-min periods" case were similar to those for the "all 30-min periods" case for both grass and wheat. Results were somewhat different for the "stable periods" case, particularly for wheat and on 7 July, 4 and 5 September for grass. In general, differences between unstable and stable conditions were not as high as reported by Moore (1986) but they were higher than those reported by Villalobos (1997). Table 7 summarizes the frequencies of $z / L$ values computed for grass and wheat. Most were within the range of -1.0 to 0.5 . Under these conditions, small differences among the surface layer co-spectra of $\overline{w^{\prime} t^{\prime}}$ (or $\overline{w^{\prime} q^{\prime}}$ ) for stable or unstable conditions can be expected (Kaimal and Finnigan, 1994).

Some people may argue that differences between lysimeter and eddy covariance system were due to the different surface area "sensed" by these two instruments rather than the horizontal sensor displacement. It is true that weighing lysimeters only "sense" the Iysimeter surface area, in this case $6.3 \mathrm{~m}^{2}$, strictly speaking, while eddy covariance systems "sense" a much larger surface area. Thus, following ASCE (1996), it was estimated that about 85 to $90 \%$ of fluxes detected by the eddy covariance system used in this research were generated within the upwind fetch distance. Nevertheless, weighing lysimeters are claimed to precisely measure water losses from soil and vegetated surfaces as long as several requirements are met (Allen et al., 1991; ASCE, 1996; Jensen et al., 1990). These requirements include using similar management practices inside and outside the lysimeter, avoiding footprints next to the lysimeter, minimum spacing between the inner and outer lysimeter tanks, thin lysimeter walls and others. These requirements were met in this research and so it can be assumed that lysimeter $L E$ values do represent fluxes occurring in the surrounding field plot.

Crop height $(h)$ varied between 0.14 to $0.18 \mathrm{~m}$ during the analyzed period for grass. If zero-plane displacement $(d)$ is computed as $d=2 / 3$ $h$, then sensor height above zero-plane displacement $\left(z_{d}=z-d\right)$ varied between 0.33 to $0.36 \mathrm{~m}$. Subsequently, the ratio $\left(\mathrm{s} / \mathrm{z}_{d}\right)$ of horizontal sensor displacement $(s)$ to $z_{d}$ was about 0.36 to 0.39 for measurements 
over grass. The loss in covariance for $L E$ observed for grass in this study were in general of the same magnitude as that reported by Villalobos (1997).

For wheat, crop height was $0.90 \mathrm{~m}$ and zero-plane displacement was about $0.60 \mathrm{~m}$. Sensor height above zero-plane displacement $\left(z_{d}\right)$ was $1.15 \mathrm{~m}$. The ratio $\left(s / z_{d}\right)$ of sensor horizontal separation (s) to $z_{d}$ was about 0.11 . The better agreement between $L E_{\text {lys }}$ and $L E_{e c}$ observed for wheat may be due to the lower $s / z_{d}$ ratio. Other studies support these results. Villalobos (1997) studied the fractional loss in covariance as a function of the $s / z_{d}$ ratios and extrapolated his results to suggest that this loss could be greatly reduced for $s / z_{d}$ ratios of about 0.1 . Moore (1986) also suggested that horizontal sensor separation should not exceed $10 \%$ of $z_{d}$. Experimental and theoretical work on temperature and vertical wind speed suggests that for $s / z_{d}$ ratios of 0.1 , more than $90 \%$ of the flux is recovered (Kristensen et al., 1997). Dugas et al. (1991) reported significant $L E$ underestimation by eddy covariance when compared to a Bowen ratio system for a wheat crop during two days in April, with a $s / z_{d}$ ratio of about 0.1 . In that study, the crop was at an earlier development stage for which higher $L E$ values would have been expected.

LE values over grass may had another source of error as measurements were made too close to the grass surface. This may have resulted in missing high frequency eddies containing a considerable portion of the flux near the surface. In this situation, loss in covariance observed for grass may be due to horizontal sensor displacement as well as the problem just mentioned. Another problem is the flow distortion due to supporting sensor masts. However, loss in covariance for $L E$ was much higher on 15 July than the other days studied over grass. Predominant wind directions on 15 July were south south east (SSE), east south east (ESE), and SE. Likely, not all periods for which flow distortions due to supporting sensor masts occurred have been removed, and these distortions were enhanced by the proximity of sensors to the surface. On the other hand, a similar situation regarding to wind direction occurred on May 26, 1999 over wheat but a close agreement between $L E_{l y s}$ and $L E_{e c}$ was observed. Measurements over wheat were taken much higher and so distortions due to proximity of sensors to the surface and supporting sensor masts were reduced. Wyngaard (1981) and Foken and Wichura (1996) have pointed out that the effect of flow distortion depends on the turbulence integral scale which changes in the open air with height, wind velocity, stratification and roughness.

The results discussed so far show that it is more appropriate to use low $s / z_{d}$ ratios in order to reduce loss of covariance of $L E$ measured by an eddy covariance system. Again, it should be reminded that energy balance closure was not achieved for grass but it was for wheat 
in most cases. In general terms losses in covariance for $H$ and $L E$ were similar to those shown by Villalobos (1997).

Further analysis of the correction proposed by Villalobos (1997) was conducted by applying equation 1 . For that, the ratios of $\overline{w^{\prime} T_{1}^{\prime}}$ to $\overline{w^{\prime} T_{2}^{\prime}}$ were computed for both grass and wheat for each 30-min period available. At first glance, and based on regression slopes listed in Table 5 , ratios lying within the range 0.8 to 2.0 approximately should be expected. However, surprisingly, there was a significant amount of $\overline{w^{\prime} T_{1}^{\prime}}$ to $\overline{w^{\prime} T_{2}^{\prime}}$ ratios outside this range as shown by the relative frequencies of different ranges of those ratios (Table 8).

For grass, only $15 \%$ of those ratios were within the 0.8 to 2.0 range on 17 July. No single day showed a relative frequency larger than $70 \%$ for that range, except 31 July. For wheat, relative frequencies for the range 0.8 to 2.0 were above $60 \%$ for all days and above $80 \%$ for five of the studied days. These results were due to the fact that $\overline{w^{\prime} T_{1}^{\prime}}$ to $\overline{w^{\prime} T_{2}^{\prime}}$ ratios become unbounded when $\overline{w^{\prime} T_{2}^{\prime}}$ approaches zero. This problem was particularly apparent during stable periods when $H$ values were usually small.

Subsequently, equation 1 was only applied for those 30-min periods for which $\overline{w^{\prime} T_{1}^{\prime}}$ to $\overline{w^{\prime} T_{2}^{\prime}}$ ratios were within the range of 0.8 to 2.0 . Table 9 shows the corresponding regression analyses between $L E_{\text {lys }}$ (dependent variable) and: a) $L E_{e c}$; and b) $L E_{e c v}$. The index of agreement $(I A)$, as defined by Willmott (1982), was computed (Appendix 1) in order to describe differences among compared values. This statistic is both a relative and bounded measure $(0<I A<1)$. For grass, the regression slopes and the $I A$ values indicate that a significant better agreement (but not complete) between $L E_{e c v}$ and $L E_{l y s}$ was achieved. The best results were obtained for 31 July (regression slope of 1.01 and $I A=$ $0.97)$. In this day, all $\overline{w^{\prime} T_{1}^{\prime}}$ to $\overline{w^{\prime} T_{2}^{\prime}}$ ratios were within the range of 1.0 to 2.0. The improvement observed on 15 July was high but still the difference between $L E_{l y s}$ and eddy covariance $L E$ was important due to the problems already discussed associated with this day. Most of $\overline{w^{\prime} T_{1}^{\prime}}$ to $\overline{w^{\prime} T_{2}^{\prime}}$ ratios on 17 July were outside the 0.8 to 2.0 range and only few 30-min periods were left for analysis.

The results for wheat (Table 9) indicate a poorer agreement between $L E_{e c v}$ and $L E_{l y s}$. In this case, $L E_{e c}$ was slightly larger than $L E_{l y s}$ though not significantly, while $H_{e c}$ was slightly larger than $H_{t 2}$ (Table 5). In this situation, an improvement of the agreement between eddy covariance and lysimeter $L E$ values should not be expected when applying Villalobos method. A significant improvement of the energy balance closure was achieved after applying the scheme correction of Villalobos (1997) for grass but not for wheat (Table 6) in accordance with the previously discussed results. 
In summary, Villalobos method may improve measurements of eddy covariance $L E$ when $s / z_{d}$ ratios are high but only if applied for some limited cases, mostly under unstable (close to neutral) atmospheric conditions. It should not be applied under stable atmospheric conditions as $\overline{w^{\prime} T_{1}^{\prime}}$ to $\overline{w^{\prime} T_{2}^{\prime}}$ ratios may be unstable and unrealistic values of $L E$ would be obtained. Alternative methods to correct the loss in covariance of $L E$ when $s / z_{d}$ ratios are high are needed. Kristensen et al. (1997) pointed out that vertical displacement rather than horizontal should be considered if vertical scalar fluxes are measured close to the ground. Kristensen et al. (1997) have shown that the loss in covariance of sensible heat fluxes is about $13 \%$ for horizontal displacement with a $s / z_{d}$ ratio of 0.2 , while the loss for vertical displacement is about $18 \%$ if the scalar sensor is positioned over the sonic anemometer but only about $2 \%$ if the scalar sensor is positioned under the sonic anemometer. Similar results could be expected for water vapor flux measurements, assuming the similarity of co-spectra for $H$ and LE (Anderson et al., 1986; Ohtaki, 1985; Redford et al., 1980).

\section{CONCLUSIONS}

The results obtained in this study show that the loss in covariance for $L E$ due to sensor horizontal displacement was in general of the same magnitude as the loss in covariance for $H$. However, this similarity depended upon atmospheric stability conditions and perhaps other factors (missing high frequency eddies near the ground, flow distortion by supporting sensor masts) that may have enhanced that loss in covariance when measuring close to the surface. Measurements over grass, with $s / z_{d}$ ratios of about 0.36 to 0.40 , showed a significant underestimation of $L E$ measured with an eddy covariance system, while measurements over wheat, with $s / z_{d}$ ratios of about 0.11 , showed a good agreement between eddy covariance and lysimeter $L E$ values.

Ratios of $\overline{w^{\prime} T_{1}^{\prime}}$ to $\overline{w^{\prime} T_{2}^{\prime}}$ have shown to be highly unbounded and unstable particularly when $H$ values were small, near zero, which may have often occurred during stable atmospheric conditions. When Villalobos method was limited to those 30 -min periods for which $\overline{w^{\prime} T_{1}^{\prime}}$ to $\overline{w^{\prime} T_{2}^{\prime}}$ ratios were within the 0.8 to 2.0 range, a significant improvement was achieved for grass. Similar results were not obtained for wheat as the observed loss in covariance was already small. Therefore, it may be concluded that Villalobos method for correcting loss in covariance of $L E$ has limited application. It should be only used when $s / z_{d}$ ratios are high and generally under unstable (close to neutral) atmospheric conditions. This method therefore has limited usefulness, particularly when long term eddy covariance measurements are pursued. 


\section{Acknowledgement}

This work has been funded by the project HID96-1295-C04-04 (Ministry of Education, Government of Spain). The author thanks Dr. Villalobos (IAS, CSIC, Córdoba, Spain) his valuable assistance in the programming of the datalogger used in the eddy covariance system. The author is also grateful to the anonymous reviewers of the manuscript for their comments and suggestions that highly improved it. Also, thanks are due to Jesús Gaudó and Miguel Izquierdo for their priceless management of the experimental fields.

\section{REFERENCES}

Allen RG, Howell TA, Pruitt WO, Walter IA, Jensen ME (eds) (1991) Lysimeters for evapotranspiration and environmental measurements, Proc. of the Int. Symp. on Lysimetry. Am. Soc. Civil Engr., New York.

Anderson DE, Verma SB, Clement RJ, Baldocchi DD, Matt DR (1986) Turbulence spectra of $\mathrm{CO}_{2}$, water vapor, temperature and velocity over a deciduous forest. Agric. For. Meteorol. 38: 81-99.

ASCE (1996) Hydrology Handbook. ASCE Manuals and Reports on Engineering Practice No. 28. Am. Soc. Civil Engr., New York.

Aubinet $M$ (1997) Comparison between different methods of measurement of momentum and sensible heat fluxes over canopies. Biotechnol. Agron. Soc. Environ. 1 (1): 17.

Baldocchi D, Meyers T (1998) On using eco-physiological, micrometeorological and biogeochemical theory to evaluate carbon dioxide, water vapor and trace gas fluxes over vegetation: a perspective. Agric. For. Meteorol. 90: 1.

Brunet Y, Itier B, McAneney J, Lagouarde JP (1994) Downwind evolution of scalar fluxes and surface resistance under conditions of local advection. Part II: measurements over barley. Agric. For. Meteorol. 71 (3-4): 227.

Campbell Scientific (1993) Making eddy correlation measurements with Campbell Scientific equipment. Technical Note 4-93MP. Shepshed, Leicester, UK. 7 pages.

Dugas WA, Fritschen LJ, Gay LW, Held AA, Matthias AD, Reicosky DC, Steduto P, Steiner JL (1991) Bowen ratio, eddy correlation, and portable chamber measurements of sensible and latent heat flux over irrigated spring wheat. Agric. For. Meteorol. 56: 1.

Dyer AJ, Garratt JR, Francey RJ, Mcllroy IC, Bacon NE, Hyson P, Bradley EF, Denmead OT, Tsvang IR, Volkov YA, Koprov BM, Elagina LG, Sahashi K, Monji N, Hanafusa T, Tsukamoto O, Frenzen P, Hicks BB, Wesely M, Miyake M, Shaw W (1982) An international turbulence comparison experiment (ITCE 1976). Boundary-Layer Meteorol. 24: 181. 
Faci JM, Martínez-Cob A, Cabezas A (1994) Agroclimatología de los regadíos del Bajo Gállego. Departamento de Agricultura, Ganadería y Montes, Diputación General de Aragón, Zaragoza.

Foken T, Dlugi R, Kramm G (1995) On the determination of dry deposition and emission of gaseous compounds at the biosphereatmosphere interface. Meteorol. Zeitschrift, N.F. 4: 91.

Foken T, Wichura B (1996) Tools for quality assessment of surfacebased flux measurements. Agric. For. Meteorol. 78: 83.

Harazono Y, Kim J, Miyata A, Choi T, Yun JI, Kim JW (1998) Measurement of energy budget components during the International Rice Experiment (IREX) in Japan. Hydrological Processes. 12 (1314): 2081.

Howell TA, Schneider AD, Dusek DA, Marek TH, Steiner JL (1995) Calibration and scale performance of Bushland weighing lysimeters. Trans. ASAE. 38 (4): 1019.

Jensen ME, Burman RD, Allen RG (eds) (1990) Evapotranspiration and irrigation water requirements. ASCE Manuals and Reports on Engr. Practice No. 70. Am. Soc. Civil Engr., New York.

Kaimal JC, Finnigan JJ (1994). Atmospheric boundary layer flows. Oxford University Press, Oxford.

Kizer MA, Elliott RL, Stone JF (1990) Hourly ET model calibration with eddy flux and energy balance data. J. Irrig. Drain. Engr. 116 (2): 172.

Koprov BM, Sokolov DY (1973) Spatial correlation functions of velocity and temperature components in the surface layer of the atmosphere. Izv. Atmos. Oceanic Phys. 9: 178-182.

Kristensen L, Mann J, Oncley SP, Wyngaard JC (1997) How close is close enough when measuring scalar fluxes with displaced sensors?. Journal of Atmospheric and Oceanic Technology. 14: 814-821.

Monteith JL, Unsworth MH (1990) Principles of environmental physics. Edward Arnold, London New York Melbourne Auckland.

Moore CJ (1986) Frequency response corrections for eddy correlation systems. Boundary-Layer Meteorol. 37: 17.

Ohtaki E (1985) On the similarity in atmospheric fluctuations of carbon dioxide, water vapor and temperature over vegetated surfaces. Bound.-Lay. Meteorol. 32: 25-37.

Redford TG, Verma SB, Rosenberg NJ (1980) Humidity fluctuations over a vegetated surface measured with a Lyman-alpha hygrometer and a fine-wire thermocouple psychrometer. J. Appl. Meteorol. 19: 860-867.

Tanner BD, Swiatek E, Greene JP (1993) Density fluctuations and use of the Krypton Hygrometer in surface flux measurements. Proc. National Conf. on Irrigation and Drainage Engineering, Irrigation and 
Drainage Division, ASCE. Park City, Utah. 21-23 July, 1993. Am. Soc. Civil Engr., New York, p 1.

Valentini R, Gamon JA, Field CB (1995) Ecosystem gas exchange in a California grassland: seasonal patterns and implications for scaling. Ecology. 76 (6): 1940.

Villalobos FJ (1997) Correction of eddy covariance water vapor flux using additional measurements of temperature. Agric. For. Meteorol. 88: 77.

Willmott CJ (1982) Some comments on the evaluation of model performance. Bull. Am. Meteorol. Soc. 63 (11): 1309-1313.

Wyngaard JC (1981) The effects of probe-induced flow distortion on atmospheric turbulence measurements. J. Appl. Meteorol. 20: 784794. 


\section{Appendix 1.}

\section{Instationarity test for checking of quality of eddy covariance data}

This test is described thoroughly by Foken and Wichura (1996). Let's assume that eddy covariance measurements are performed at a frequency $f$ during $t$ minutes such that $M$ readings are collected. Let's assume that $I$ of those $t$-min periods are combined to get eddy covariance values for It minutes. $N$ readings are collected such that $N / M=I$. Let's be $\overline{x_{i l}^{\prime} x_{j l}^{\prime}}$ the covariance of measured signals $i$ and $j$ for the $t$-min time period $I$. Then, the covariance $\overline{x_{i}^{\prime} x_{j}^{\prime}}$ for the $I t$-min time period can be computed as the arithmetic average of the $I$ covariances $\overline{x_{i l}^{\prime}} x_{j l}^{\prime}$ :

$$
\overline{x_{i}^{\prime} x_{j}^{\prime}}=\frac{1}{N / M}\left[\sum_{l=1}^{N / M} \overline{x_{i l}^{\prime} x_{j l}^{\prime}}\right]
$$

On the other hand, the value of the covariance for the full time period can also be determined according to:

$$
\overline{x_{i}^{\prime} x_{j}^{\prime}}=\frac{1}{N-1}\left[\sum_{l=1}^{N / M} \sum_{k=1}^{M} x_{i k l} x_{j k l}-\frac{1}{N}\left(\sum_{l=1}^{N / M} \sum_{k=1}^{M} x_{i k l}\right)\left(\sum_{l=1}^{N / M} \sum_{k=1}^{M} x_{j k l}\right)\right]
$$

According to Foken and Wichura (1996), the measurements can be considered as stationary if there is a difference of less than $30 \%$ between the covariances determined with equations (3) and (4).

\section{Index of agreement}

According to Willmott (1982), the index of agreement $(I A)$ is computed as follows:

$$
I A=1-\frac{\sum_{i=1}^{n}\left(y_{i}-x_{i}\right)^{2}}{\sum_{i=1}^{n}\left(\left|y_{i}-\bar{x}\right|+\left|x_{i}-\bar{x}\right|\right)^{2}}
$$

where $y_{i}$ are the values of the dependent variable $\left(L E_{l y s}\right), x_{i}$ are the values of the independent variable $\left(L E_{e c}\right.$ or $\left.L E_{e c v}\right)$ and $\bar{x}$ is the average of the independent variable. 
Table 1. Precipitation and sprinkler irrigation events during measurement time periods and crops surrounding experimental field plots.

\begin{tabular}{|c|c|c|c|c|c|l|}
\hline Time period & $\begin{array}{c}\text { Field } \\
\text { plot }\end{array}$ & \multicolumn{2}{|l|}{$\begin{array}{c}\text { Precipitation } \\
\text { events }\end{array}$} & \multicolumn{2}{|l|}{ Irrigation events } & \multicolumn{2}{c|}{$\begin{array}{c}\text { Crops } \\
\text { surrounding }\end{array}$} \\
\cline { 3 - 6 } Number & $\begin{array}{c}\text { Amount } \\
(\mathrm{mm})\end{array}$ & Number & $\begin{array}{c}\text { Amount } \\
(\mathrm{mm})\end{array}$ & \\
\hline $\begin{array}{c}\text { 1-31 Jul } \\
\text { 1997 }\end{array}$ & Grass & 7 & 37.0 & 5 & 91.0 & $\begin{array}{l}\text { Corn } \\
\text { Pastures }\end{array}$ \\
\hline $\begin{array}{c}29 \text { Aug - } \\
\text { 6 Sep 1997 }\end{array}$ & Grass & 1 & 5.8 & 2 & 31.4 & $\begin{array}{l}\text { Corn } \\
\text { Pastures }\end{array}$ \\
\hline $\begin{array}{c}\text { 14 May - } \\
\text { 9 Jun 1999 }\end{array}$ & Wheat & 5 & 21.5 & 3 & 56.7 & $\begin{array}{l}\text { Corn (early } \\
\text { stages) } \\
\text { Wheat } \\
\text { Pastures }\end{array}$ \\
\hline
\end{tabular}


Table 2. Recorded meteorological variables over grass and wheat at the automatic weather stations, measurement sensor height and sensor model.

\begin{tabular}{|c|c|c|}
\hline Variable & $\begin{array}{l}\text { Measurement } \\
\text { height }(\mathrm{m})\end{array}$ & Sensor model (manufacturer) \\
\hline $\begin{array}{l}\text { Air temperature and } \\
\text { relative humidity }\end{array}$ & $\begin{array}{l}1.50 \text { (grass) } \\
2.25 \text { (wheat) }\end{array}$ & HMP35AC (Vaisala) \\
\hline Net radiation & $\begin{array}{l}1.50 \text { (grass) } \\
2.25 \text { (wheat) }\end{array}$ & $\begin{array}{l}\text { Q-6 (Radiation and Energy } \\
\text { Balance Systems, REBS) }\end{array}$ \\
\hline Wind speed & $\begin{array}{l}2.00 \text { (grass) } \\
2.25 \text { (wheat) } \\
\end{array}$ & $\begin{array}{c}\text { Switching anemometer A100R } \\
\text { (Vector Instruments) }\end{array}$ \\
\hline Wind direction & $\begin{array}{l}2.00 \text { (grass) } \\
2.25 \text { (wheat) }\end{array}$ & $\begin{array}{c}\text { Wind vane W200P (Vector } \\
\text { Instruments) }\end{array}$ \\
\hline \multirow[t]{2}{*}{ Soil heat flux } & $\begin{array}{l}0.08 \text { (soil heat } \\
\text { flux plates) }\end{array}$ & $\begin{array}{c}\text { Two HFT1 soil heat flux plates } \\
\text { (REBS) }\end{array}$ \\
\hline & $\begin{array}{l}0.02-0.06 \text { (soil }^{0} \\
\left.\text { temperature }{ }^{1}\right)\end{array}$ & $\begin{array}{l}\text { TCAV averaging soil temperature } \\
\text { probe (Campbell Scientific) }\end{array}$ \\
\hline
\end{tabular}

1 Used to correct soil heat flux data following ASCE (1996) 
Table 3. Additional meteorological data recorded during the analyzed days. $T m$, mean air temperature. $L E R$, ratio of measured lysimeter evapotranspiration to net radiation. $W d$, predominant wind direction.

\begin{tabular}{|c|c|c|c|c|c|c|c|}
\hline \multicolumn{3}{|c|}{ Measurements over grass (1997) } & \multicolumn{3}{|c|}{ Measurements over wheat (1999) } \\
\hline Date & $\begin{array}{c}T m \\
\left({ }^{\circ} \mathrm{C}\right)\end{array}$ & LER & Wd & Date & Tm & LER & Wd (a) \\
& & & & $\left({ }^{\circ} \mathrm{C}\right)$ & & \\
\hline 07-Jul & 21.4 & 0.83 & WSW (14) & 24-May & 20.6 & 0.59 & S (17) \\
15-Jul & 24.3 & 1.15 & SSE (9) & 25-May & 21.4 & 0.55 & WSW (8) \\
17-Jul & 20.0 & 1.21 & WNW (27) & 26-May & 22.6 & 0.62 & SE (8) \\
31-Jul & 25.0 & 0.98 & WSW (19) & 03-Jun & 20.9 & 0.79 & W (12) \\
04-Sep & 20.5 & 0.75 & N (23) & 05-Jun & 20.8 & 0.65 & NW (15) \\
05-Sep & 22.7 & 0.74 & S (19) & 07-Jun & 16.9 & 0.75 & WSW (12) \\
& & & & 08-Jun & 18.8 & 0.37 & WSW (18) \\
\hline
\end{tabular}

(a) Within parenthesis, absolute frequency (number of 30-min periods) of the predominant wind direction 
Table 4. Analysis of simple linear regression $(y=c x)$ between $L E_{e c}$ (independent variable, $x$ ) and $L E_{\text {lys }}$ (dependent variable, $y$ ) for the analyzed days. $n$, number of 30 -min available periods; $R^{2}$, coefficient of determination (\%); c, regression slope.

\begin{tabular}{|c|c|c|c|c|c|c|c|c|c|}
\hline \multicolumn{10}{|c|}{ Measurements over grass (1997) } \\
\hline \multirow[t]{2}{*}{ Date } & \multicolumn{3}{|c|}{ All periods } & \multicolumn{3}{|c|}{ Unstable periods } & \multicolumn{3}{|c|}{ Stable periods } \\
\hline & $n$ & $R^{2}$ & C & $n$ & $R^{2}$ & $c$ & $n$ & $R^{2}$ & $c$ \\
\hline 07-Jul & 45 & $97.5^{\mathrm{s}}$ & $1.52^{\mathrm{s1}}$ & 29 & $98.4^{\mathrm{s}}$ & $1.55^{\mathrm{s} 1}$ & 16 & $87.6^{\mathrm{s}}$ & $1.06^{\mathrm{ns} 1}$ \\
\hline $15-J u l$ & 39 & $89.6^{\mathrm{s}}$ & $2.46^{\mathrm{s1}}$ & 11 & $91.5^{\mathrm{s}}$ & $2.35^{\mathrm{s} 1}$ & 28 & $87.2^{\mathrm{s}}$ & $2.71^{\mathrm{s} 1}$ \\
\hline $17-J u l$ & 47 & $71.0^{\mathrm{s}}$ & $1.52^{\mathrm{s} 1}$ & 17 & $81.7^{\mathrm{s}}$ & $1.55^{\mathrm{s} 1}$ & 30 & $34.5^{\mathrm{s}}$ & $1.35^{\mathrm{ns} 1}$ \\
\hline $31-J u l$ & 47 & $94.3^{\mathrm{s}}$ & $1.52^{\mathrm{s} 1}$ & 18 & $95.9^{\mathrm{s}}$ & $1.54^{\mathrm{s} 1}$ & 29 & $80.7^{\mathrm{s}}$ & $1.39^{\mathrm{s} 1}$ \\
\hline 04-Sep & 40 & $85.7^{\mathrm{s}}$ & $1.14^{\mathrm{ns} 1}$ & 18 & $94.1^{\mathrm{s}}$ & $1.15^{\mathrm{ns} 1}$ & 22 & $0.2^{\mathrm{ns}}$ & $0.19^{\mathrm{ns} 1}$ \\
\hline $05-$ Sep & 45 & $91.7^{\mathrm{s}}$ & $1.42^{\mathrm{s} 1}$ & 19 & $98.0^{\mathrm{s}}$ & $1.44^{\mathrm{s}}$ & 26 & $31.6^{\mathrm{s}}$ & $1.04^{\mathrm{ns} 1}$ \\
\hline \multicolumn{10}{|c|}{ Measurements over wheat (1999) } \\
\hline \multirow[t]{2}{*}{ Date } & \multicolumn{3}{|c|}{ All periods } & \multicolumn{3}{|c|}{ Unstable periods } & \multicolumn{3}{|c|}{ Stable periods } \\
\hline & $n$ & $R^{2}$ & c & $n$ & $R^{2}$ & $c$ & $n$ & $R^{2}$ & $c$ \\
\hline 24-May & 42 & $92.5^{\mathrm{s}}$ & $1.04^{\mathrm{ns} 1}$ & 25 & $94.2^{\mathrm{s}}$ & $1.04^{\mathrm{ns} 1}$ & 17 & $78.5^{\mathrm{s}}$ & $0.99^{\mathrm{ns} 1}$ \\
\hline 25-May & 47 & $94.5^{\mathrm{s}}$ & $0.97^{\mathrm{ns} 1}$ & 24 & $96.1^{\mathrm{s}}$ & $0.97^{\mathrm{ns} 1}$ & 23 & $75.4^{\mathrm{s}}$ & $1.19^{\mathrm{ns} 1}$ \\
\hline 26-May & 40 & $92.0^{\mathrm{s}}$ & $0.97^{\mathrm{ns} 1}$ & 17 & $95.4^{\mathrm{s}}$ & $0.96^{\mathrm{ns} 1}$ & 23 & $69.8^{s}$ & $1.16^{\mathrm{ns} 1}$ \\
\hline 03-Jun & 43 & $97.1^{\mathrm{s}}$ & $0.94^{\mathrm{ns} 1}$ & 23 & $97.5^{\mathrm{s}}$ & $0.94^{\mathrm{ns} 1}$ & 20 & $91.2^{\mathrm{s}}$ & $0.99^{\mathrm{ns} 1}$ \\
\hline 05-Jun & 47 & $94.5^{\mathrm{s}}$ & $0.93^{\mathrm{ns} 1}$ & 18 & $96.2^{\mathrm{s}}$ & $0.94^{\mathrm{ns} 1}$ & 29 & $77.3^{\mathrm{s}}$ & $0.86^{\mathrm{ns} 1}$ \\
\hline 07-Jun & 36 & $73.3^{s}$ & $0.92^{\mathrm{ns} 1}$ & 20 & $78.7^{\mathrm{s}}$ & $0.90^{\mathrm{ns} 1}$ & 16 & $50.4^{s}$ & $1.07^{\mathrm{ns} 1}$ \\
\hline 08-Jun & 45 & $87.4^{\mathrm{s}}$ & $0.71^{\mathrm{s} 1}$ & 25 & $91.6^{\mathrm{s}}$ & $0.70^{\mathrm{s1}}$ & 20 & $45.3^{s}$ & $0.89^{n}$ \\
\hline
\end{tabular}


Table 5. Analysis of simple linear regression $(y=c x)$ between $H_{t 2}$ (independent variable, $x$ ) and $H_{e c}$ (dependent variable, $y$ ) for the analyzed days. $n$, number of 30 -min available periods; $R^{2}$, coefficient of determination (\%); $c$, regression slope.

\begin{tabular}{|c|c|c|c|c|c|c|c|c|c|}
\hline \multicolumn{10}{|c|}{ Measurements over grass (1997) } \\
\hline \multirow[t]{2}{*}{ Date } & \multicolumn{3}{|c|}{ All periods } & \multicolumn{3}{|c|}{ Unstable periods } & \multicolumn{3}{|c|}{ Stable periods } \\
\hline & $n$ & $R^{2}$ & $c$ & $n$ & $R^{2}$ & & $n$ & $R^{2}$ & 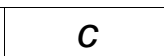 \\
\hline 07-Jul & 45 & $93.5^{\mathrm{s}}$ & $1.34^{\mathrm{s} 1}$ & 29 & $94.7^{\mathrm{s}}$ & $.28^{\mathrm{s1}}$ & 16 & $97.3^{s}$ & $1.93^{\mathrm{s} 1}$ \\
\hline & 39 & & & 11 & 91 & s1 & 28 & $96.5^{\mathrm{s}}$ & \\
\hline & 47 & $.9^{\mathrm{s}}$ & 0.8 & 17 & $87.8^{s}$ & $0.91^{\mathrm{ns} 1}$ & 30 & $93.3^{s}$ & $0.73^{\mathrm{s} 1}$ \\
\hline & 47 & $99.8^{\mathrm{s}}$ & & 18 & $99.9^{\mathrm{s}}$ & $1.48^{\mathrm{s} 1}$ & 29 & $99.5^{\mathrm{s}}$ & $1.46^{\mathrm{s} 1}$ \\
\hline & 40 & $94.3^{\mathrm{s}}$ & & 18 & $95.6^{\mathrm{s}}$ & 1.1 & 22 & $97.2^{\mathrm{s}}$ & \\
\hline 05 & 45 & $93.9^{\mathrm{s}}$ & $1.39^{\circ}$ & 19 & $94.2^{\mathrm{s}}$ & $1.38^{\mathrm{s1}}$ & 26 & $91.3^{\mathrm{s}}$ & \\
\hline \multicolumn{10}{|c|}{ nts over wheat (1999 } \\
\hline \multirow[t]{2}{*}{ Date } & \multicolumn{3}{|c|}{ All periods } & \multicolumn{3}{|c|}{ Unstable periods } & \multicolumn{3}{|c|}{ Stable periods } \\
\hline & $n$ & $R^{2}$ & & $n$ & $R^{2}$ & - & $n$ & $R^{2}$ & 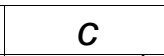 \\
\hline ay & 42 & $97.9^{\mathrm{s}}$ & $1.12^{\mathrm{s} 1}$ & 25 & 98.4 & $1.10^{\mathrm{s1}}$ & 17 & $97.3^{s}$ & 1.41 \\
\hline & 47 & & & 24 & & & 23 & $96.1^{\mathrm{s}}$ & \\
\hline & 40 & $98.9^{\mathrm{s}}$ & 0.9 & 17 & $99.2^{\mathrm{s}}$ & $0.95^{\mathrm{ns} 1}$ & 23 & $99.6^{\mathrm{s}}$ & $1.14^{\mathrm{s} 1}$ \\
\hline 03-Jun & 43 & $99.5^{\mathrm{s}}$ & 1.03 & 23 & $99.7^{\mathrm{s}}$ & $1.03^{s 1}$ & 20 & $98.1^{\mathrm{s}}$ & $0.98^{\mathrm{ns} 1}$ \\
\hline & 47 & $98.4^{\mathrm{s}}$ & $1.09^{s 1}$ & 18 & $98.6^{\mathrm{s}}$ & 1.0 & 29 & $97.4^{\mathrm{s}}$ & $0.85^{\mathrm{s}}$ \\
\hline Jun & 36 & $99.4^{\mathrm{s}}$ & $1.05^{\mathrm{s} 1}$ & 20 & $99.5^{\mathrm{s}}$ & $1.06^{\mathrm{s} 1}$ & 16 & $99.6^{\mathrm{s}}$ & $0.95^{\mathrm{s} 1}$ \\
\hline 08-Jun & 45 & $99.6^{\mathrm{s}}$ & $1.05^{\mathrm{s} 1}$ & 25 & $99.6^{\mathrm{s}}$ & $1.05^{\mathrm{s} 1}$ & 20 & $98.7^{\mathrm{s}}$ & $1.03^{\mathrm{ns}}$ \\
\hline
\end{tabular}

significant $(\alpha=0.95)$

${ }^{\text {s1 }}$ Significantly different than $1(\alpha=0.95)$

${ }^{\mathrm{ns} 1}$ Not significantly different than $1(\alpha=0.95)$ 
Table 6. Closure numbers obtained for grass and wheat. Case I, all 30min periods available. Case $\mathrm{II}$, only $30-\mathrm{min}$ periods for which $\overline{w^{\prime} T_{1}^{\prime}}$ to $\overline{w^{\prime} T_{2}^{\prime}}$ ratios were within the $[0.8,2.0]$ range: $\left.I I-a\right)$ before applying the scheme correction of Villalobos (1997); II-b) after applying the scheme correction of Villalobos (1997).

\begin{tabular}{|c|c|c|c|c|c|c|}
\hline \multicolumn{7}{|c|}{ Measurements over grass (1997) } \\
\hline \multirow[b]{3}{*}{ Date } & \multicolumn{3}{|c|}{ Absolute values $\left(\mathrm{W} \mathrm{m}^{-2}\right)$} & \multicolumn{3}{|c|}{ Relative values (1) } \\
\hline & \multirow[b]{2}{*}{ Case I } & \multicolumn{2}{|c|}{ Case II } & \multirow[b]{2}{*}{ Case I } & \multicolumn{2}{|c|}{ Case II } \\
\hline & & $\mathrm{II}-\mathrm{a}$ & II-b & & $\mathrm{II}-\mathrm{a}$ & $11-b$ \\
\hline 7 July & 77.1 & 112.8 & 70.6 & 26.4 & 39.0 & 18.4 \\
\hline 15 July & 87.9 & 85.5 & 56.1 & 44.0 & 42.7 & 16.9 \\
\hline 17 July & 39.3 & 100.3 & 36.7 & 13.9 & 37.6 & 9.3 \\
\hline 31 July & 72.2 & 72.2 & 17.4 & 25.2 & 25.2 & 4.1 \\
\hline 4 September & 55.9 & 52.3 & 42.7 & 24.0 & 22.4 & 12.3 \\
\hline 5 September & 83.9 & 82.7 & 62.2 & 29.5 & 29.1 & 12.1 \\
\hline \multicolumn{7}{|c|}{ Measurements over wheat (1999) } \\
\hline & \multicolumn{3}{|c|}{ Absolute values $\left(\mathrm{W} \mathrm{m}^{-2}\right)$} & \multicolumn{3}{|c|}{ Relative values (1) } \\
\hline & \multirow[b]{2}{*}{ Case I } & \multicolumn{2}{|c|}{ Case II } & & \multicolumn{2}{|c|}{ Case II } \\
\hline Date & & $11-a$ & II-b & Case I & II-a & II-b \\
\hline 24 May & 32.6 & 45.7 & 27.8 & 12.4 & 17.5 & 8.5 \\
\hline 25 May & 32.1 & 46.5 & 37.7 & 10.7 & 15.5 & 11.8 \\
\hline 26 May & 42.2 & 45.5 & 44.7 & 15.5 & 16.9 & 15.2 \\
\hline 3 June & -7.6 & 8.2 & -0.1 & -2.3 & 2.5 & 0.0 \\
\hline 5 June & -7.0 & 9.6 & -6.3 & -2.7 & 3.8 & -2.3 \\
\hline 7 June & -1.4 & -0.5 & -4.0 & -1.0 & -0.4 & -3.0 \\
\hline 8 June & -13.6 & -13.6 & -17.3 & -7.3 & -7.3 & -8.4 \\
\hline
\end{tabular}

(1) As percentage of the whole range of $L E_{e c}$ values for that particular day. 
Table 7. Relative frequencies (\%) of different ranges of $z / L$ values computed during the analyzed days.

\begin{tabular}{|c|c|c|c|c|c|}
\hline \multicolumn{7}{|c|}{ Measurements over grass (1997) } \\
\hline \multirow{2}{*}{ Date } & \multicolumn{7}{|c|}{ Ranges of $z / L$ values } \\
\cline { 2 - 6 } & $\leq-1.0$ & $(-1.0,0.0]$ & $(0.0,0.5]$ & $(0.5,1.0]$ & 1.0 \\
\hline 07-Jul & 2.2 & 62.2 & 31.1 & 0.0 & 4.4 \\
15-Jul & 2.6 & 25.6 & 71.8 & 0.0 & 0.0 \\
17-Jul & 0.0 & 36.2 & 63.8 & 0.0 & 0.0 \\
31-Jul & 0.0 & 38.3 & 61.7 & 0.0 & 0.0 \\
04-Sep & 20.0 & 25.0 & 52.5 & 2.5 & 0.0 \\
05-Sep & 15.6 & 26.7 & 51.1 & 4.4 & 2.2 \\
\hline \multicolumn{7}{|c|}{ Ranges of $z / L$ values } \\
\hline Date & \multicolumn{7}{|c|}{ Measurements over wheat (1999) } \\
\cline { 2 - 6 } 24-May & 11.9 & 47.6 & 33.3 & 7.1 & 0.0 \\
25-May & 14.9 & 36.2 & 48.9 & 0.0 & 0.0 \\
26-May & 5.0 & 37.5 & 35.0 & 12.5 & 10.0 \\
03-Jun & 2.3 & 51.2 & 46.5 & 0.0 & 0.0 \\
05-Jun & 10.6 & 27.7 & 61.7 & 0.0 & 0.0 \\
07-Jun & 19.4 & 36.1 & 44.4 & 0.0 & 0.0 \\
08-Jun & 2.2 & 53.3 & 44.4 & 0.0 & 0.0 \\
\hline
\end{tabular}


Table 8. Relative frequencies (\%) of different ranges of $\overline{w^{\prime} T_{1}^{\prime}}$ to $\overline{w^{\prime} T_{2}^{\prime}}$ ratios during the analyzed days.

\begin{tabular}{|c|c|c|c|c|}
\hline \multirow{2}{*}{ Date } & \multicolumn{4}{|c|}{ Reanges of $\overline{w^{\prime} T_{1}^{\prime}}$ to $\overline{w^{\prime} T_{2}^{\prime}}$ ratios } \\
\cline { 2 - 5 } & $\leq 0.8$ & $(0.8,1.0]$ & $(1.0,2.0]$ & $>2.0$ \\
\hline 07-Jul & 26.7 & 6.7 & 42.2 & 24.4 \\
15-Jul & 25.6 & 17.9 & 51.3 & 5.1 \\
17-Jul & 76.6 & 4.3 & 10.6 & 8.5 \\
31-Jul & 0.0 & 0.0 & 100.0 & 0.0 \\
04-Sep & 25.0 & 10.0 & 55.0 & 10.0 \\
05-Sep & 4.4 & 15.6 & 51.1 & 28.9 \\
\hline \multicolumn{5}{|c|}{ Ranges of $\overline{w^{\prime} T_{1}^{\prime}}$ to $\overline{w^{\prime} T_{2}^{\prime}}$ ratios } \\
\hline Date & Measurements over wheat & \multicolumn{1}{c|}{ rag9) } \\
\cline { 2 - 5 } & $\leq 0.8$ & $(0.8,1.0]$ & $(1.0,2.0]$ & $>2.0$ \\
24-May & 19.0 & 16.7 & 57.1 & 7.1 \\
25-May & 10.6 & 19.1 & 61.7 & 8.5 \\
26-May & 12.5 & 22.5 & 65.0 & 0.0 \\
03-Jun & 18.6 & 27.9 & 53.5 & 0.0 \\
05-Jun & 36.2 & 29.8 & 31.9 & 2.1 \\
07-Jun & 2.8 & 47.2 & 50.0 & 0.0 \\
08-Jun & 0.0 & 51.1 & 48.9 & 0.0 \\
\hline
\end{tabular}


Table 9. Analysis of simple linear regression $(y=c x)$ between $L E_{l y s}$ (dependent variable, $y$ ) and: a) $L E_{E C}$; and b) $L E_{e c c v}$. Only for those 30 -min periods for which $\overline{w^{\prime} T_{1}^{\prime}}$ to $\overline{w^{\prime} T_{2}^{\prime}}$ ratios were within the $[0.8,2.0]$ range during the analyzed days. $n$, number of $30-$ min available periods; $R^{2}$, coefficient of determination $(\%) ; c$, regression slope; $I A$, index of agreement.

\begin{tabular}{|c|c|c|c|c|c|c|c|}
\hline \multicolumn{8}{|c|}{ Measurements over grass (1997) } \\
\hline \multirow[t]{2}{*}{ Date } & \multirow[t]{2}{*}{$n$} & \multicolumn{3}{|c|}{$L E_{\text {lys }}$ vs $L E_{e c}$} & \multicolumn{3}{|c|}{$L E_{\text {lys }}$ vs $L E_{e c v}$} \\
\hline & & $R^{2}$ & $c$ & IA & $R^{2}$ & c & IA \\
\hline $07-\mathrm{Jul}$ & 22 & $90.0^{\mathrm{s}}$ & $1.53^{\mathrm{si}}$ & 0.873 & $80.7^{\mathrm{s}}$ & $1.17^{\mathrm{s} 1}$ & 0.937 \\
\hline $15-\mathrm{Jul}$ & 28 & $76.9^{s}$ & $2.42^{\mathrm{s} 1}$ & 0.657 & $78.9^{s}$ & $1.65^{\mathrm{s} 1}$ & 0.836 \\
\hline $17-\mathrm{Jul}$ & 7 & $60.8^{\mathrm{s}}$ & $1.93^{\mathrm{s} 1}$ & 0.628 & $47.5^{\mathrm{s}}$ & $1.35^{\mathrm{ns} 1}$ & 0.801 \\
\hline $31-J u l$ & 47 & $86.6^{\mathrm{s}}$ & $1.52^{\mathrm{s1}}$ & 0.875 & $86.9^{\mathrm{s}}$ & $1.01^{\mathrm{ns} 1}$ & 0.970 \\
\hline 04-Sep & 26 & $70.2^{\mathrm{s}}$ & $1.21^{\mathrm{s} 1}$ & 0.919 & $62.2^{\mathrm{s}}$ & $0.93^{\mathrm{ns} 1}$ & 0.925 \\
\hline 05-Sep & 30 & $77.0^{\mathrm{s}}$ & $1.35^{\mathrm{s1}}$ & 0.909 & $74.0^{\mathrm{s}}$ & $0.88^{\mathrm{ns} 1}$ & 0.949 \\
\hline \multicolumn{8}{|c|}{ Measurements over wheat (1999) } \\
\hline \multirow[t]{2}{*}{ Date } & \multirow[t]{2}{*}{$n$} & \multicolumn{3}{|c|}{$L E_{l y s}$ vs $L E_{e c}$} & \multicolumn{3}{|c|}{$L E_{\text {lys }}$ vs $L E_{e c v}$} \\
\hline & & $R^{2}$ & $C$ & IA & $R^{2}$ & c & IA \\
\hline 24-May & 31 & $81.6^{\mathrm{s}}$ & $1.05^{\mathrm{ns} 1}$ & 0.958 & $76.6^{\mathrm{s}}$ & $0.89^{s 1}$ & 0.945 \\
\hline 25-May & 38 & $85.9^{s}$ & $0.98^{\mathrm{ns} 1}$ & 0.972 & $85.5^{\mathrm{s}}$ & $0.91^{\mathrm{s} 1}$ & 0.968 \\
\hline 26-May & 35 & $84.5^{\mathrm{s}}$ & $0.97^{\mathrm{ns} 1}$ & 0.968 & $84.2^{s}$ & $0.98^{\mathrm{ns} 1}$ & 0.967 \\
\hline 03-Jun & 35 & $88.1^{\mathrm{s}}$ & $0.94^{\mathrm{s} 1}$ & 0.975 & $88.3^{s}$ & $0.90^{\mathrm{s} 1}$ & 0.971 \\
\hline 05-Jun & 29 & $77.0^{\mathrm{s}}$ & $0.94^{\mathrm{ns} 1}$ & 0.950 & $66.3^{s}$ & $0.82^{\mathrm{s} 1}$ & 0.903 \\
\hline 07-Jun & 35 & $34.2^{\mathrm{s}}$ & $0.92^{\mathrm{ns} 1}$ & 0.764 & $33.3^{s}$ & $0.84^{\mathrm{ns} 1}$ & 0.772 \\
\hline 08-Jun & 45 & $66.9^{s}$ & $0.71^{\mathrm{s} 1}$ & 0.869 & $65.3^{s}$ & $0.66^{\mathrm{s} 1}$ & 0.847 \\
\hline
\end{tabular}

significant $(\alpha=0.95)$

s1 Significantly different than $1(\alpha=0.95)$

${ }^{\text {ns1 }}$ Not significantly different than $1(\alpha=0.95)$ 
Figure 1. Net radiation for 30-min periods recorded over grass (1997). 
Figure 2. Net radiation for 30-min periods recorded over wheat (1999). 
Figure 3. Results of the instationarity test (Foken and Wichura, 1996) for the 30-min $\overline{w^{\prime} q}$ values computed from equation (3) and equation (4) (Appendix 1), respectively. 
Figure 4. Evapotranspiration rate measured for 30-min periods with a weighing lysimeter $\left(E T_{\text {lys }}\right)$ and an eddy covariance system $\left(E T_{\text {ec }}\right)$ over grass (1997). Boxes show the total daily values (using only available 30 -min periods) for both variables. 
Figure 5. Evapotranspiration rate measured for 30-min periods with a weighing lysimeter $\left(E T_{\text {lys }}\right)$ and an eddy covariance system $\left(E T_{\text {ec }}\right)$ over wheat (1999). Boxes show the total daily values (using only available 30 -min periods) for both variables. 
Figure 6. Sensible heat flux measured for 30-min periods with an eddy covariance system over grass (1997): a) using a thermocouple attached to a sonic anemometer $\left(H_{e c}\right)$; b) using a second thermocouple attached to an hygrometer $\left(H_{t 2}\right)$. Boxes show the average daily values (using only available 30-min periods) for both variables. 
Figure 7. Sensible heat flux measured for 30-min periods with an eddy covariance system over wheat (1999): a) using a thermocouple attached to a sonic anemometer $\left(H_{e c}\right) ;$ b) using a second thermocouple attached to an hygrometer $\left(H_{t 2}\right)$. Boxes show the average daily values (using only available 30-min periods) for both variables. 


\section{FIGURE CAPTIONS}

Figure 1. Net radiation for 30-min periods recorded over grass (1997).

Figure 2. Net radiation for 30-min periods recorded over wheat (1999).

Figure 3. Results of the instationarity test (Foken and Wichura, 1996) for the 30-min $\overline{W^{\prime} q}$ values computed from equation (3) and equation (4) (Appendix 1), respectively.

Figure 4. Evapotranspiration rate measured for 30-min periods with a weighing lysimeter $\left(E T_{\text {lys }}\right)$ and an eddy covariance system $\left(E T_{e c}\right)$ over grass (1997). Boxes show the total daily values (using only available 30 -min periods) for both variables.

Figure 5. Evapotranspiration rate measured for 30-min periods with a weighing lysimeter $\left(E T_{\text {lys }}\right)$ and an eddy covariance system $\left(E T_{\text {ec }}\right)$ over wheat (1999). Boxes show the total daily values (using only available 30-min periods) for both variables.

Figure 6 . Sensible heat flux measured for 30-min periods with an eddy covariance system over grass (1997): a) using a thermocouple attached to a sonic anemometer $\left(H_{e c}\right)$; b) using a second thermocouple attached to an hygrometer $\left(H_{t 2}\right)$. Boxes show the average daily values (using only available 30-min periods) for both variables.

Figure 7. Sensible heat flux measured for 30-min periods with an eddy covariance system over wheat (1999): a) using a thermocouple attached to a sonic anemometer $\left(H_{e c}\right) ;$ b) using a second thermocouple attached to an hygrometer $\left(H_{t 2}\right)$. Boxes show the average daily values (using only available 30-min periods) for both variables. 

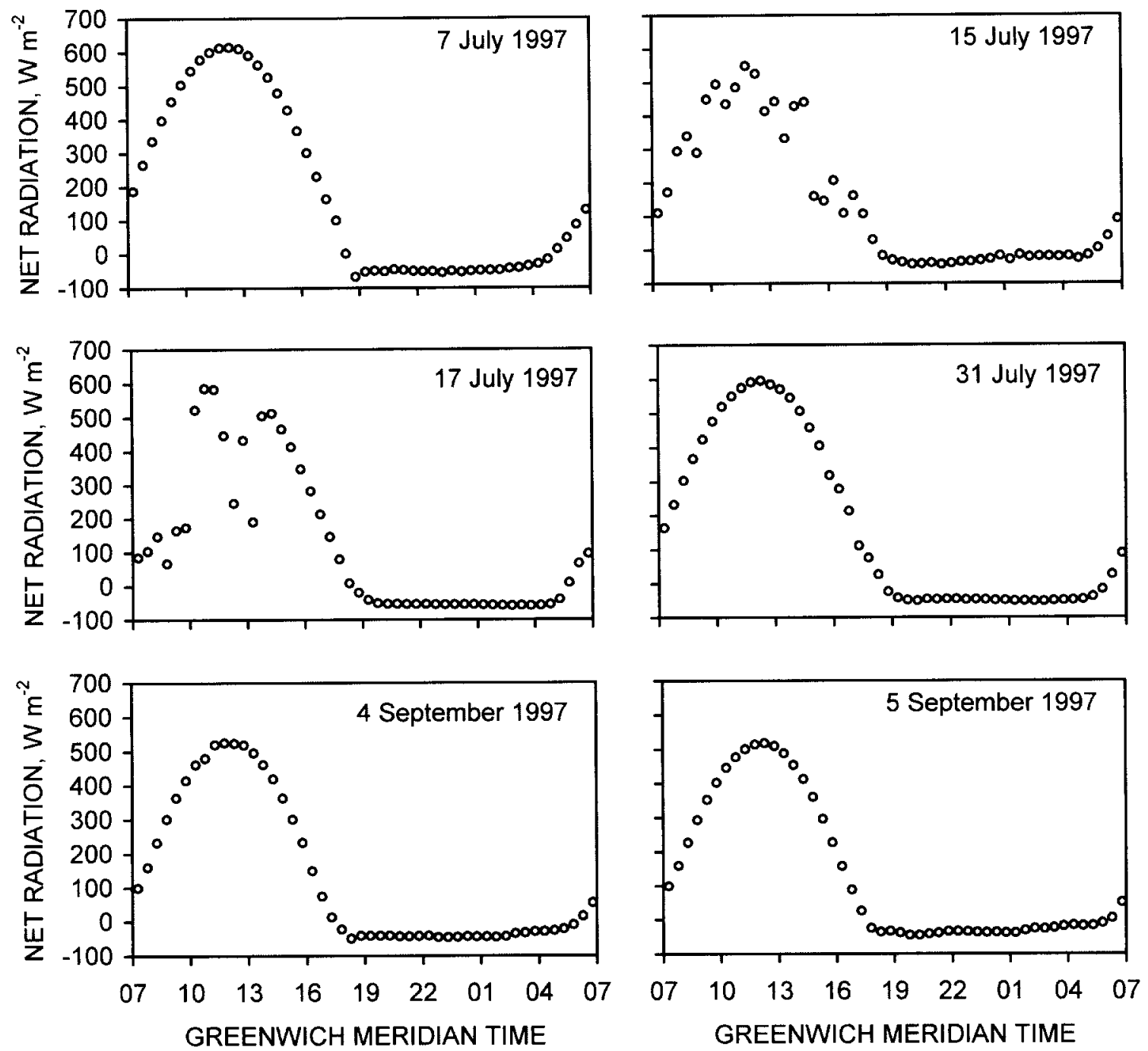

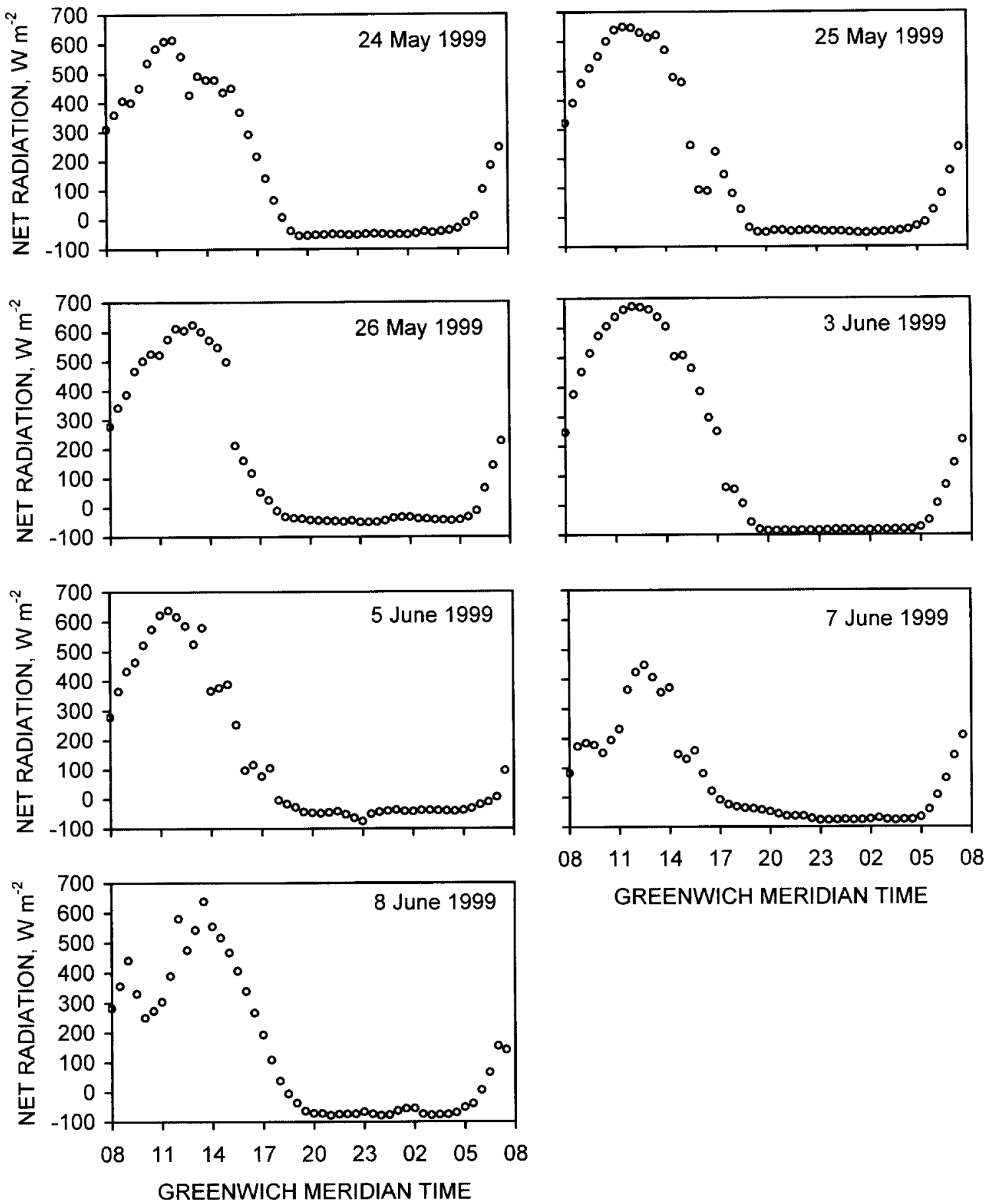

GREENWICH MERIDIAN TIME 

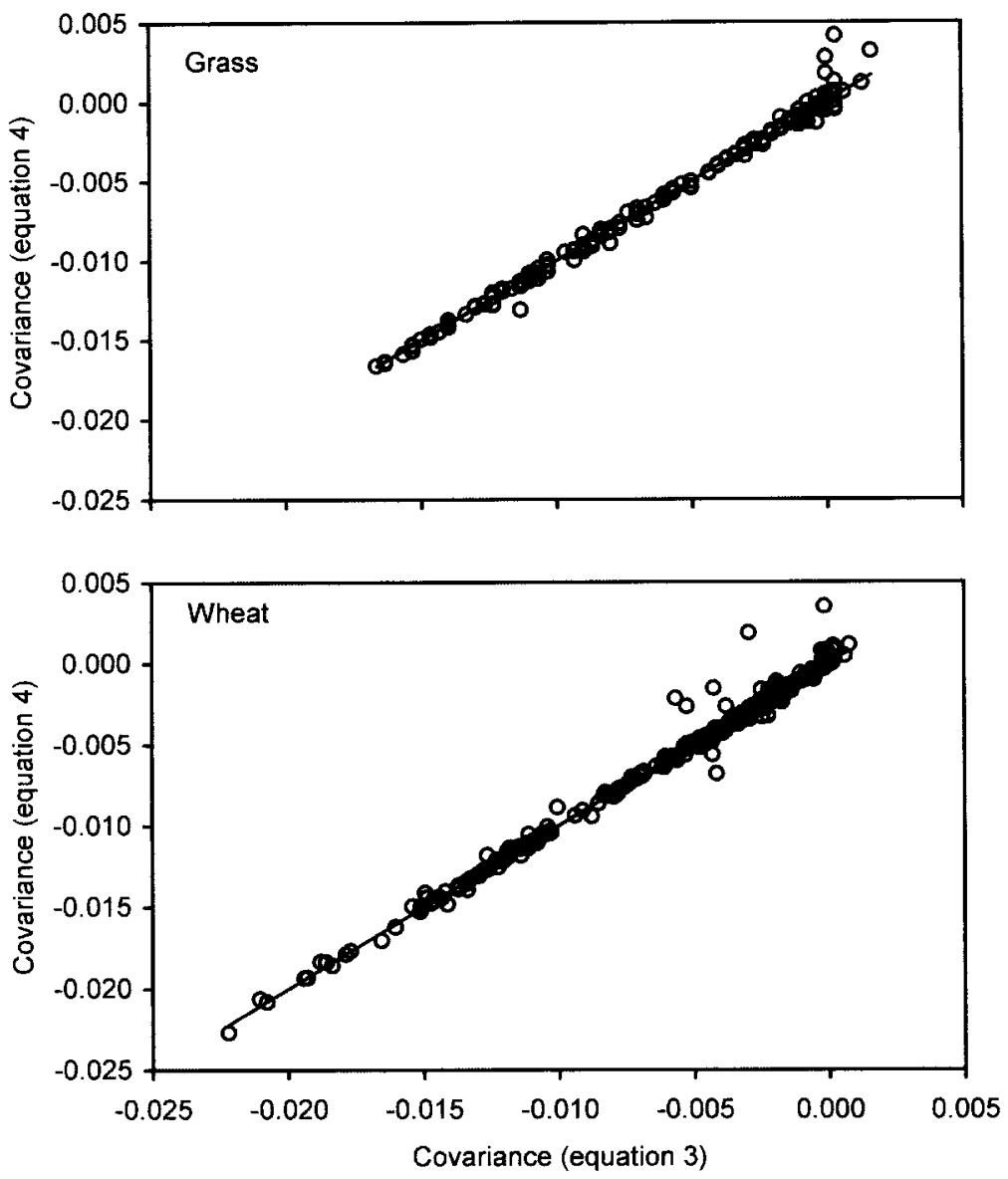

- $\operatorname{Cov}($ eq. 4$)-$ Line 1:1 

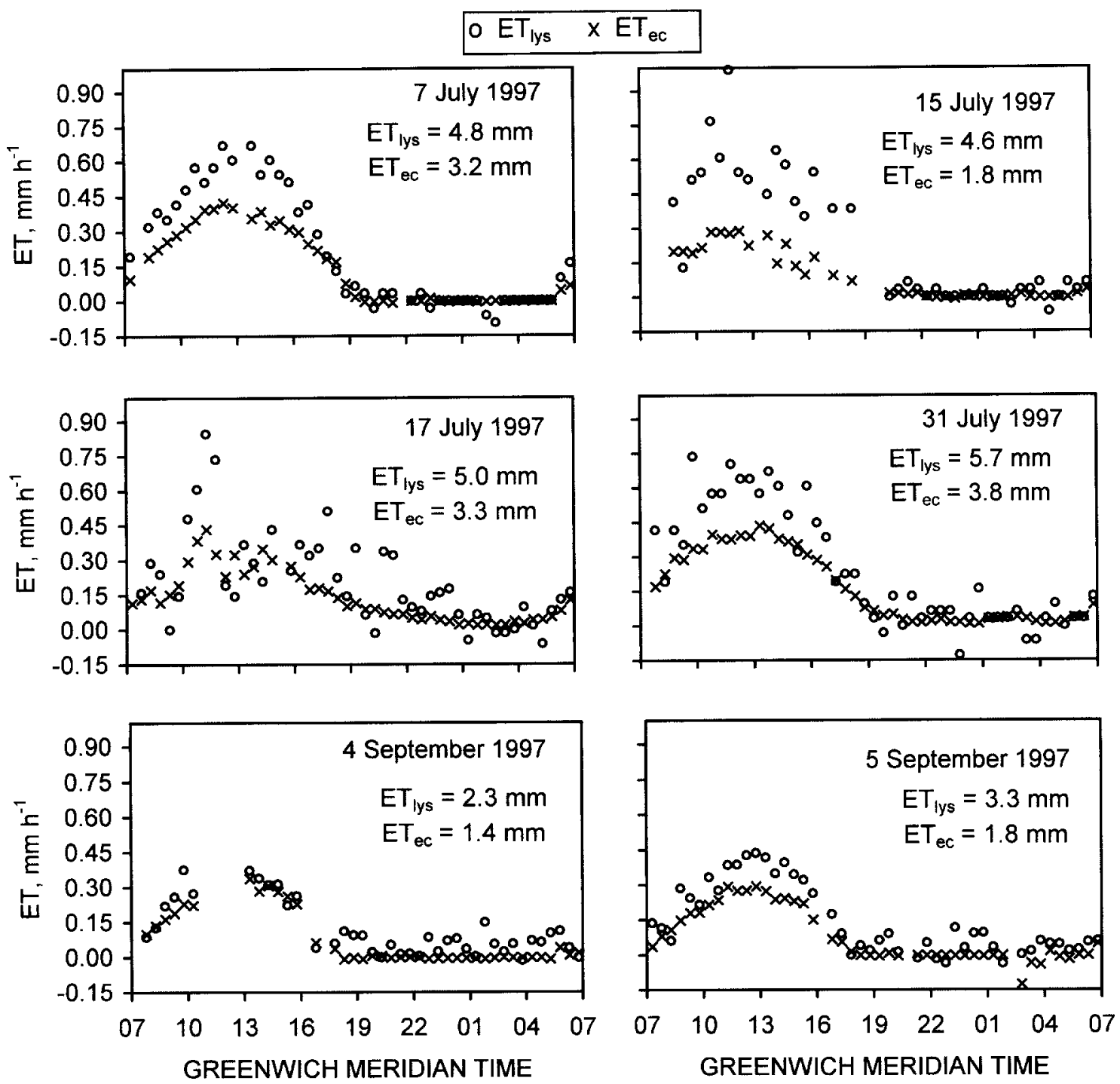


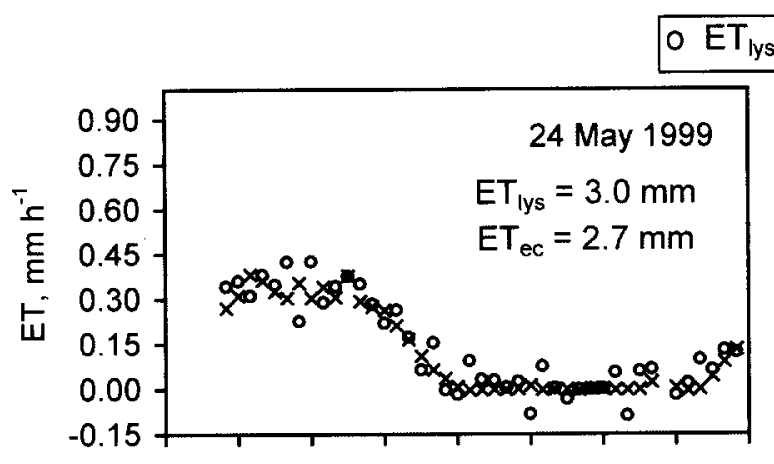

\section{$\times E^{e c}$}
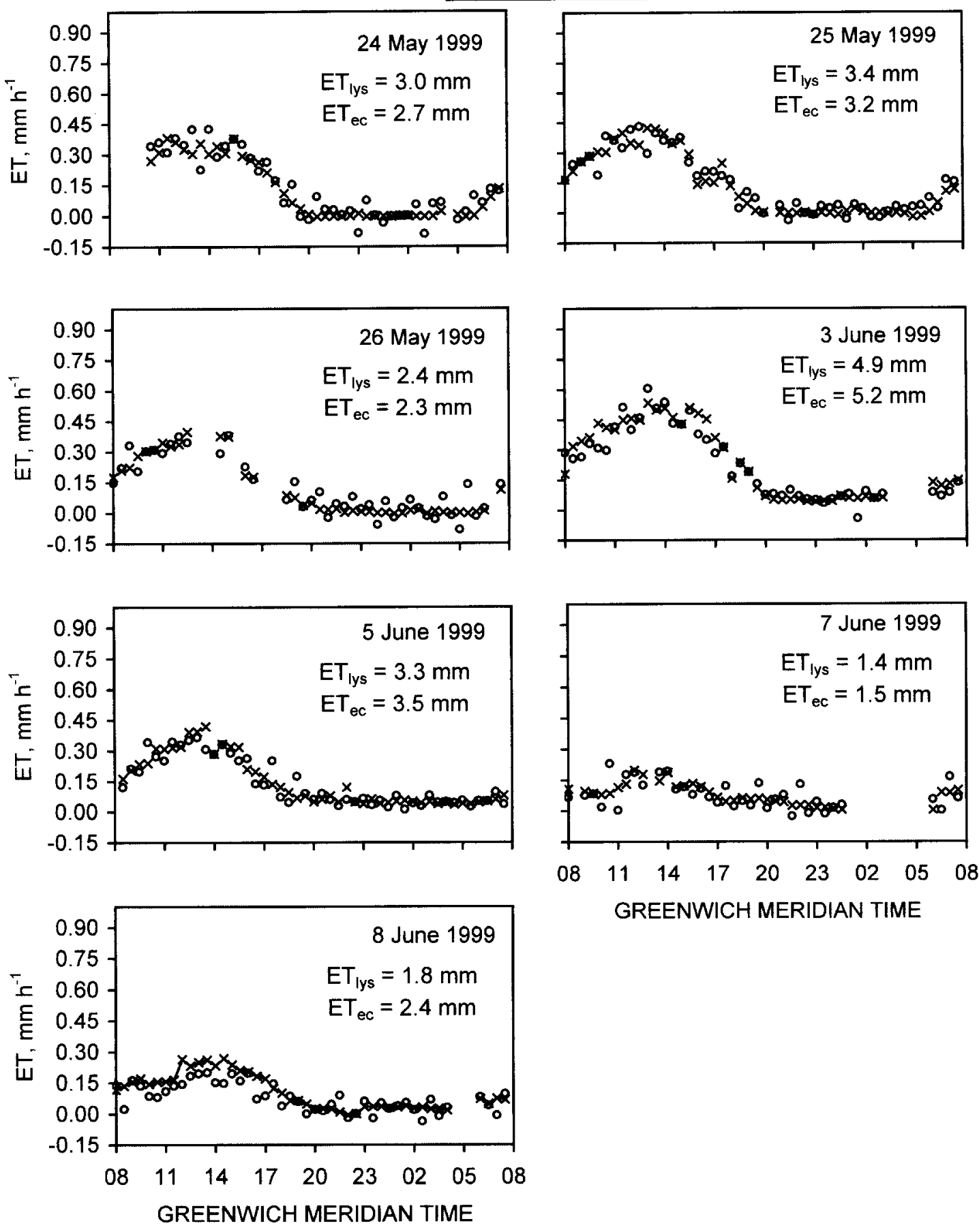

GREENWICH MERIDIAN TIME 


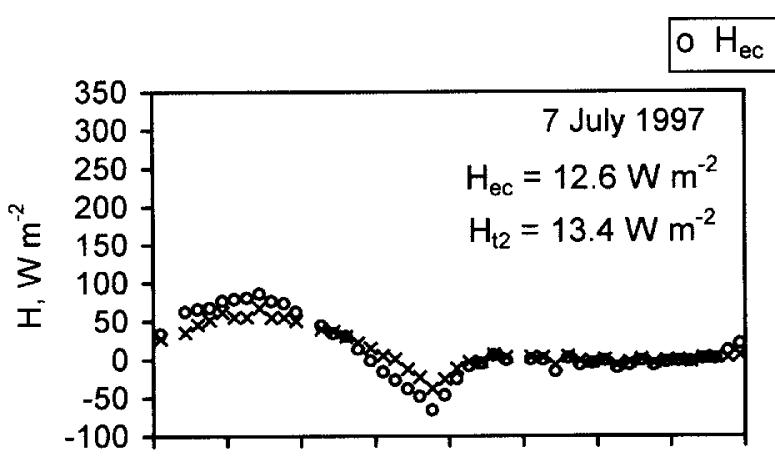

$$
\begin{array}{r}
15 \text { July } 1997 \\
H_{e c}=0.0 \mathrm{~W} \mathrm{~m}^{-2} \\
H_{t 2}=-0.6 \mathrm{~W} \mathrm{~m}^{-2}
\end{array}
$$

${ }_{x \rightarrow 2}^{2} \times$
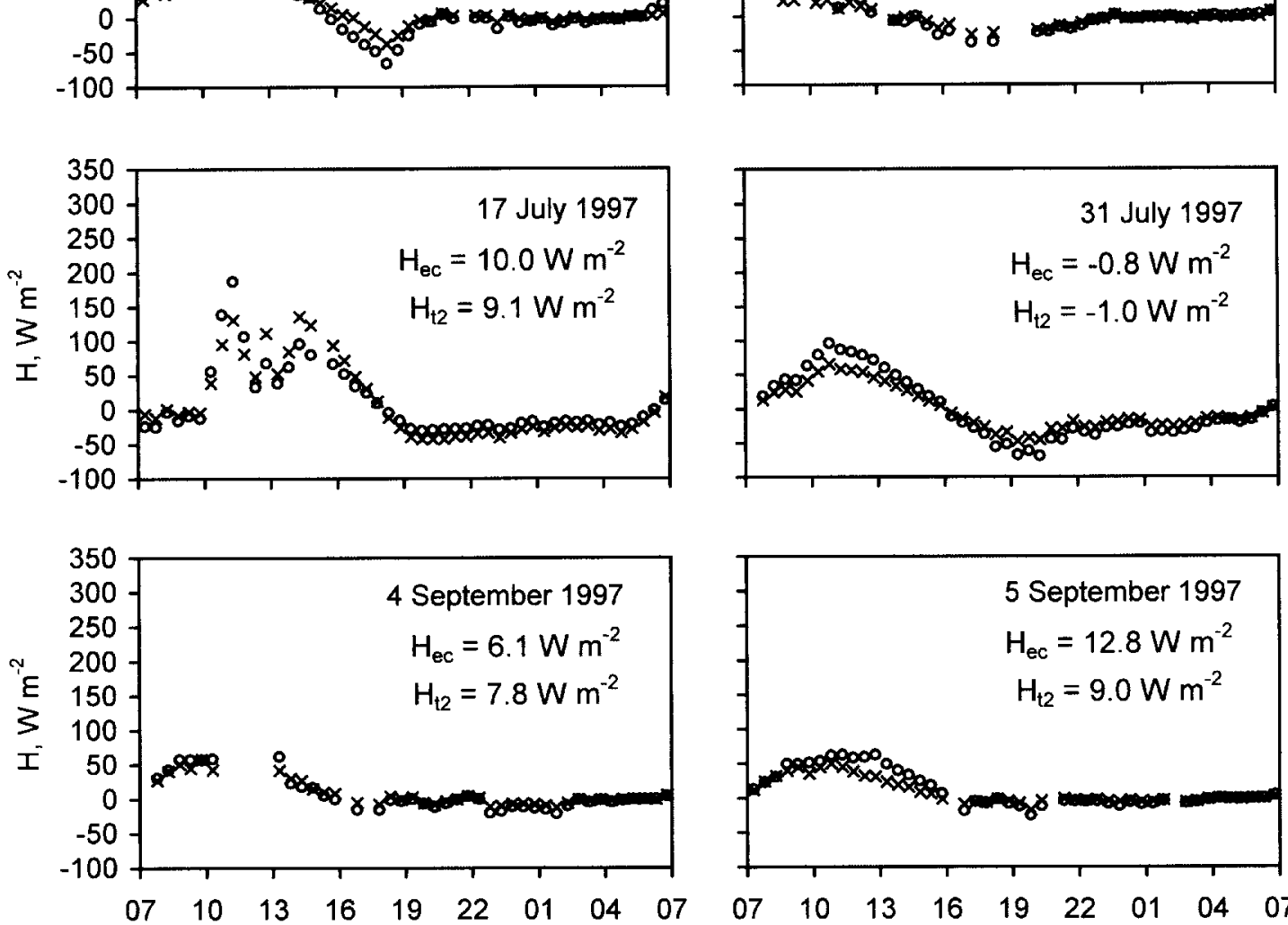

GREENWICH MERIDIAN TIME

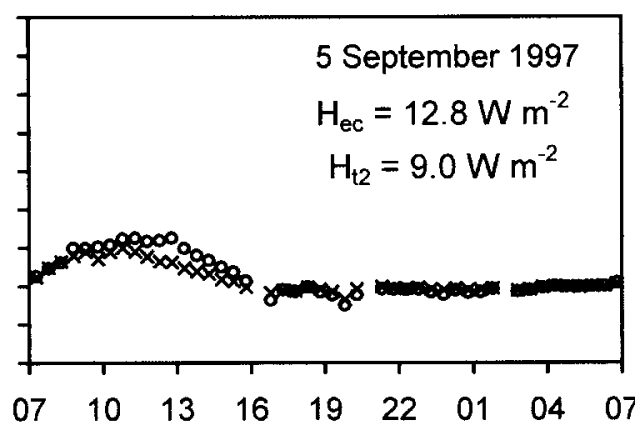

GREENWICH MERIDIAN TIME 

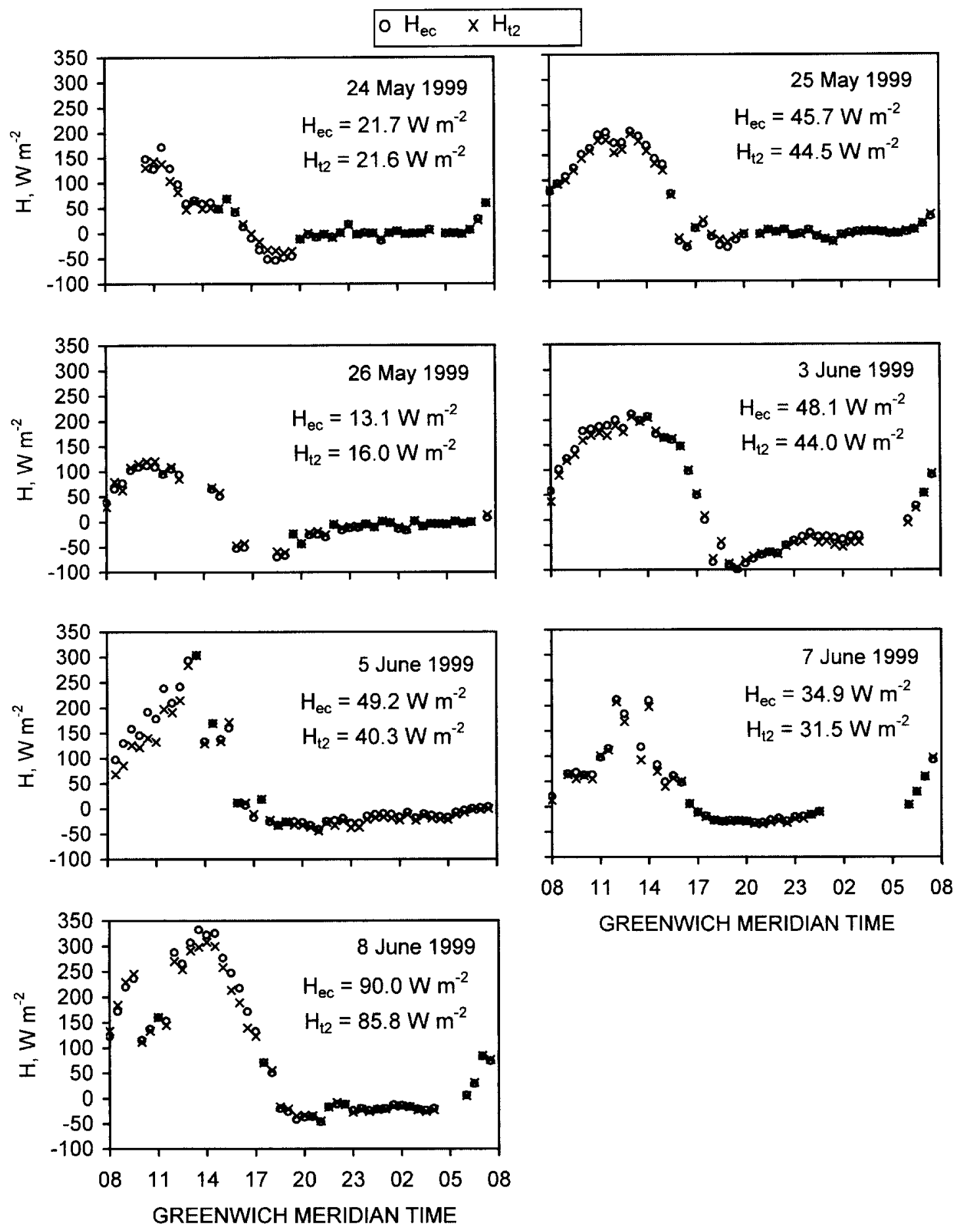

GREENWICH MERIDIAN TIME 